\title{
LAS ASOCIACIONES SINDICALES DE FUNCIONARIOS EN LA ADMINISTRACION LOCAL
}

342.728: 352.084 .3

por

\author{
Angel Sánchez Blanco \\ Del Departamento de Derecho Administrativo \\ de la Facultad de Derecho de Salamanca
}

SUMARIO: I. INTRODUCCION.-II. APRECIACIONES SOBRE EL AMBITO TERRITORIAL Y FUNCIONAL CUBIERTO POR LAS ASOCIACIONES SINDICALES DE FUNCIONARIOS DE LA ADMINISTRACION LOCAL: 1. ASOCIACIONES DE AMBITO ESTATAL. 2. ASOCIACIONES DE ÁMBITO REgIONAL. 3. Asociaciones DE ÁMBITO PROVINCIAL. 4. Asociaciones de AMbITo ComarCal. 5. AsociacioNES DE AMBITO LOCAL.-III. EL AMBITO SUBJETIVO CUBIERTO POR LAS ASOCIACIONES SINDICALES DE FUNCIONARIOS DE LA ADMINISTRACION LOCAL. EL CONTRASTE ENTRE LA REGULACION NORMATIVA Y LA PRACTICA ASOCIATIVA.-IV. APRECIACIONES FINALES.-V. APENDICE: ASOCIACIONES DE FUNCIONARIOS DE LA ADMINISTRACION LOCAL.

\section{INTRODUCCION}

Superados con amplitud los dos años desde la aprobación y publicación del Real Decreto.1522/1977, de 17 de junio (BOE 2 de julio), regulador del derecho de asociación sindical de los funcio- 
narios públicos, puede considerarse oportuno el tratar de apreciar el desarrollo operativo que la mencionada disposición ha tenido en el ámbito de la Administración local y, de modo especial, en referencia a los funcionarios que, por no estar vinculados a los Cuerpos Nacionales de la Administración Local, carecen de cobertura colegial, como efecto inducido de la disolución de los Colegios de Funcionarios Locales no pertenecientes a Cuerpos Nacionales, por Orden del Ministerio del Interior de 17 de marzo de 1978.

Con esta finalidad ha sido elaborada la relación de las Asociaciones de Funcionarios Locales constituidas, desde el comienzo de la entrada en vigor del mencionado Real Decreto 1522/1977, de 17 de junio, hasta el 31 de octubre de 1979, con el objetivo de apreciar las líneas maestras que han orientado la constitución de estas asociaciones. La fuente de información utilizada para esta elaboración se materializa en los anuncios publicados en el Boletín Oficial del Estado por el Servicio de Registro de Organizaciones de Funcionarios de la Presidencia del Gobierno, posteriormente denominado Servicio de Asuntos Sindicales.

Aunque obvio, estimo conveniente advertir que, si bien la relación de asociaciones se ha hecho con la precisa minuciosidad que exigía el deseo de no omitir ninguna asociación constituida, entra en el terreno de lo posible la existencia de alguna omisión, situación que lamentaría, pero que disculpa el método de trabajo impuesto, por no haber podido utilizar una relación oficial de asociaciones y ser ésta producto de la consulta diaria del $B O E$, concurriendo la circunstancia de que los anuncios publicados en el Boletín no desglosan las asociaciones sindicales de funcionarios constituidas en el ámbito de la Administración central, institucional, corporativa o local. Asimismo significo que en este trabajo no se entra a analizar los estatutos de las asociaciones, por dificultades insuperables en la obtención de una muestra significativa que, por otra parte no aportaría precisiones de relieve para esta aproximación al fenómeno asociativo de los funcionarios de la Administración local. Tampoco se realizan estimaciones cualitativas referidas a las distintas asociaciones como consecuencia de dificultades, aún de mayor entidad, en la obtención de datos fidedignos sobre el número de afiliados, ámbito geográfico realmente cubierto por la asociación, actividades profesionales..., precisiones que, por otra parte, serían más propias de un estudio sociológico. No obstante, sí se considera, con base en los datos aportados por los anuncios en 
el $B O E$, el ámbito subjetivo cubierto por las asociaciones estudiadas y las características y problemática que este tema suscita en la práctica, en contraste con la posición que, al respecto, mantiene la normativa reguladora de las asociaciones de funcionarios.

En el apéndice de este trabajo ofrezco relación de las Asociaciones de los Funcionarios de Administración Local constituidas en el período julio de 1977 a octubre de 1979, clasificadas según la sistemática del ámbito geográfico cubierto por su actuación, ámbito que nos obliga a establecer el modelo estatal-regional-provincialcomarcal-local, con la subespecialidad que determina la constitución de asociaciones de funcionarios en determinadas Diputaciones provinciales, situándose estas asociaciones entre el ámbito provincial, determinado por las competencias de la Diputación provincial y el ámbito local determinado por la particularización de la Diputación provincial como centro administrativo. El criterio clasificatorio territorial se completa con la concreción de las asociaciones de carácter general y las asociaciones de carácter sectorial, entendiendo por asociaciones generales aquellas que tienen como ámbito subjetivo un colectivo de funcionarios unidos por el factor homogéneo de pertenecer a una Corporación local o a las Corporaciones locales implicadas en el ámbito comarcal, provincial, regional o nacional cubierto por la asociación sindical. La idea de asociaciones sectoriales la individualizamos con base en la peculiaridad de integrar a colectivos de funcionarios cualificados por su especialidad profesional como funcionarios de la Administración local.

Con apoyo en los datos incluidos en los distintos apartados de este apéndice, hacemos las apreciaciones que siguen.

\section{APRECIACIONES SOBRE EL AMBITO TERRITORIAL $Y$ FUNCIONAL CUBIERTO POR LAS ASOCIACIONES SINDICALES DE FUNCIONARIOS DE LA ADMINISTRACION LOCAL}

\section{Asociaciones de Ámbito estatal}

Las asociaciones constituidas con ámbito estatal se concretan en la Unión Federal Independiente de Trabajadores de la Administración Local (UFITAL), constituida en el mes de octubre de 1977, y en la Unión de Sindicatos Independientes de la Administración 
Local (USIAL), constituida en el mes de febrero de 1979. Ambas Asociaciones presentan peculiaridades que las diferencian entre sí. UFITAL está orientada por el objetivo de integrar a todos los funcionarios de la Administración local, provincial y regional (1), prejuzgando, en este sentido, la adscripción de los funcionarios al servicio de las Comunidades autónomas en el ámbito de la Administración local, siendo de retener el dato de que pretende integrar a funcionarios, personas físicas. En contraste con los criterios que orientan la composición subjetiva de UFITAL, la Unión de Sindicatos Independientes de la Administración Local (USIAL), en concordancia con la denominación bajo la que se particulariza, opta por el criterio organizativo de pretender integrar a las organizaciones de funcionarios, personas jurídicas. Como puede observarse, es clara la contraposición de criterios en la determinación de los componentes subjetivos de ambas Asociaciones, orientadas, en cuanto a su ámbito espacial, por la pretensión de comprender todo el territorio del Estado. No obstante, recentrándonos en el diferente ámbito subjetivo de las dos Asociaciones, es factible observar que en esa diferencia parece que ha radicado la operatividad de USIAL y las dificultades funcionales que han gravitado sobre UFITAL, cuya virtualidad operativa ha estado obstaculizada por la dificultosa pretensión de duplicar, en octubre de 1977, y de un modo inorgánico, la figura del Colegio de Funcionarios Locales no pertenecientes a Cuerpos Nacionales. En contraste con este criterio organizativo, la alternativa de USIAL de integrar no personas físicas, sino organizaciones asociativas, ha significado una iniciativa más realista, desconectada de planteamientos que parecían demasiado afines a las antiguas estructuras colegiales y que, al encontrar base subjetiva en los núcleos funcionariales más inquietos, radicados, como tendremos ocasión de apreciar, en las Asociaciones del Ayuntamiento y Diputación de Madrid y en las organizaciones asturianas y alicantinas, ha podido erigirse, de hecho, en la única organización asociativa sindical de los funcionarios de la Administración local con eficaz proyección en el ámbito estatal, y su posición se fortalece, en el doble nivel, del práctico desplazamiento de asociaciones sindicales competitivas y de no ser menoscabada su operatividad por la interferencia de organizaciones específicas de funcionarios locales vinculadas a centrales sindicales, como consecuencia de la opción de las centrales por estructuras

(1) BOE de 28 de octubre de 1977. 
organizativas que parecen participar de la idea del carácter omnicomprensivo de la categoría función pública (2), idea de la que también participan algunas asociaciones sindicales de funcionarios constituidas con la pretensión de aglutinar a funcionarios de la Administración local con funcionarios de la Administración central e institucional y que adquieren, en consecuencia, carácter interadministrativo (3).

(2) Las centrales sindicales articulan su estructura organizativa en el ámbito fun. cionarial con un criterio omnicompresivo e integrador de los distintos funcionarios al servicio de la Administración central, regional, local e institucional, a nivel territorial estatal y provincial. Este es el criterio seguido por las centrales sindicales CC.OO., UGT y USO.

CC.OO. tiene constituida la Federación Sindical de Comisiones de la Administiación Pública (BOE 29 de julio de 1977) y la mayor parte de las Provincias españolas tienen formado su sindicato provincial de comisiones de la función pública, sin perjuicio de organizaciones sectoriales, especialmente en el ámbito de la enseñanza.

La misma orientación caracteriza a USO con una organización de ámbito estatal: Unión Sindical de Trabajadores de la Administración de la USO (USTA-USO) y con el espectro provincial en gran parte cubierto por sus uniones sindicales de trabajadores de ámbito provincial, a la vez que, con ámbito sectorial, tiene constituida la Federación de Trabajadores de Correos y Telégrafos de la Unión Sindical Obrera (FTCE-USO) (BOE 21 de abril de 1978) y la Federación Provincial de Trabajadores de la Enseñanza de la Unión Sindical Obrera (BOE 13 de julio de 1978), esta última con una apreciable incidencia provincial.

El mismo esquema organizativo presenta UGT con su Federación de Sindicatos de Trabajadores de la Administración Pública (FETAP) (BOE 29 de julio de 1977), a nivel estatal general, y su Sindicato Nacional de Correos y Telégrafos, de la Federación Nacional de Comunicaciones de la UGT (BOE 9 de febrero de 1978-27 de mayo de 1978), y su Federación de Sindicatos de Trabajadores de la Enseñanza (FETE-UGT) ( $B O E 12$ de mayo de 1978). La UGT presenta la particularidad de que la incidencia, a nivel provincial, de las dos federaciones sectoriales es notablemente mayor que la incidencia de organizaciones generales de funcionarios constituidas con nivel provincial. Para mayores precisiones sobre este punto me remito a mi trabajo Las Asociaciones Sindicales de Funcionarios en la Administración Central, Institucional y Corporativa, de próxima publicación.

(3) En esta línea están las asociaciones generales, con ámbito territorial estatal, regional y provincial, independientes de centrales sindicales y que pretenden integrar a los colectivos de funcionarios públicos existentes en su ámbito territorial, sin diferenciación en el encuadre administrativo de éstos. Como muestra podemos citar: con nivel estatal, la Confederación Sindical de Funcionarios (CSF Independiente) (BOE 6 de enero de 1978, 26 de abril de 1979 y 27 de julio de 1979); a nivel regional, la asociación sindical «Sindicat de Treballadors de l'Administraciò de Catalunya» (BOE 6 de agosto de 1977), el Sindicato Galego de Traballadores de Administración Pública (BOE 28 de diciembre de 1977) o el Sindicato de Trabajadores de la Aáministración Pública del País Vasco (BOE 22 de junio de 1978). Con ámbito provincial cabe citar la Asociación Profesional de Funcionarios Públicos y Personal Contratado en Régimen de Derecho Administrativo de Santa Cruz de Tenerife (BOE 5 de septiembre de 1979), ejemplo prácticamente único al mencionado nivel provincial. De las asociaciones sectoriales interadministrativas también se encuentra una muestra no minimizable y que cubre la triparticipación estatal, regional, provincial, afectando de modo especial a profesionales con titulación académica de Escuelas Técnicas, a los cuerpos generales de los Ministerios de Obras Públicas y Urbanismo y Transportes y Comunicaciones, y a los titulados y licenciados conexos con la Sanidad. Puede encontrarse una relación y valoración de estas asociaciones en mi precitado trabajo Las Asociaciones Sindicales de Funcionarios en la Administración Central, Institucional y Corporativa. 
Al mismo nivel estatal y con carácter sectorial sólo es constatable la existencia de la Asociación Profesional de Secretarios Habilitados al Servicio de las Corporaciones Locales, que constituye, en el cuadro de las asociaciones estudiadas, la única implicada con Cuerpos Nacionales de la Administración local, respecto de los cuales es ratificada la observación del profesor BOQUERA OLIVER, según la cual algunos cuerpos actúan y han actuado como verdaderas agrupaciones profesionales, hecho especialmente notorio para los secretarios, interventores y depositarios agrupados en una organización colegial, de tal modo que la figura de la asociación resulta innecesaria para estos funcionarios, actuando, simultáneamente, como estímulo para la unión de los funcionarios no bien situados (4), estímulo que, sin duda, actúa en relación con el colectivo de los secretarios habilitados, que ofrece la paradoja, no precisamente imputable en exclusiva a los miembros de esta categoría funcionarial, de definir como profesional una situación administrativa, tan peculiar, en su acceso y ejercicio, como la habilitación.

\section{ASOCIACIONES DE AMBITo REgIONAL}

Las asociaciones sindicales de funcionarios de Administración local que, con carácter general, pretenden integrar en su seno a todos los funcionarios que prestan sus servicios en cada una de las Nacionalidades o Regiones del Estado, se limitan a la Federación de Sindicatos Asturianos de la Administración Local, al Sindicato Unitario de Administración Local de la Región Andaluza, Ceuta y Melilla y a la Unión de Funcionarios de la Administración Local de Baleares. La muestra no puede ser considerada como brillante ni es posible afirmar que se aproxime a la configuración del ya complejo mapa preautonómico de las Nacionalidades y Regiones del Estado. Desde esta perspectiva llama la atención la circunstancia de que las asociaciones sindicales constituidas a nivel regional tomen como referencia a tres Regiones: Asturias, Andalucía y Baleares, que presentan la particularidad de no ser las más conflictivas desde el punto de vista de la incidencia de la vertebración del modelo regional sobre el tejido orgánico de la Administración local preexis-

(4) Sobre esta problemática, vid. BOQUERA Oliver: «Las Asociaciones de Funcionarios», en esta REvisTA, núm. 195 (1977), pág. 491. Incidiendo en el tema, Sosa WAGNER: «Libertades públicas y Funcionarios», Revista Española de Derecho Administrativo, núm. 17 (1978), pág. 177. 
tente. En este sentido resulta chocante que, en contraposición con la problemática suscitada por la autonomía catalana, al plantear la desaparición de las Diputaciones provinciales y configurar un modelo territorial comarcal, con las veguerías, como unidades administrativas de segundo grado integradoras de las unidades básicas locales, los funcionarios de Administración local, a los que de modo ineludible afectará la reorganización territorial, no encuentren en estas medidas, con tanta trascendencia para ellos, los necesarios incentivos para articular sus opiniones y posiciones en una asociación sindical de ámbito regional. La misma reflexión suscita la conflictiva problemática vinculada a la autonomía del País Vasco, en la que los Ayuntamientos han sido y son punto de referencia en la materialización de las tensiones, sin olvidar los problemas lingüísticos o los simplemente administrativos de mejorar el régimen jurídico de la relación funcional, aprovechando la dinámica del cambio generado por la institucionalización regional..., conjunto de factores que podían haber estimulado la articulación de los criterios y demandas de los funcionarios de la Administración local en torno a la figura de la asociación sindical de funcionarios. No obstante, y a pesar de que las condiciones concurrentes en los más cualificados entes preautonómicos y en los funcionarios de la Administración local, en cuanto incididos por la actividad de estas entidades, pudiera hacer pensar en la adecuación de las asociaciones sindicales de funcionarios al ámbito geográfico delimitado por las autonomías de Nacionalidades y Regiones, las asociaciones constituidas son cortas en número y no se ajustan a la hipótesis de que la mayor conflictividad de las autonomías para los funcionarios podría generar un mayor dinamismo asociativo. La carencia de virtualidad de este principio, que parece anular el mecanismo sindical de acción-reacción, encuentra continuidad en las asociaciones sindicales sectoriales constituidas al mismo nivel regional.

El espectro que, desde el punto de vista de los entes regionales, cubre el asociacionismo sectorial vuelve a remitirnos a la Región asturiana, con base en la Asociación de Funcionarios Técnicos de los Ayuntamientos de Asturias y, en otro ámbito regional, incorpora a las asociaciones de técnicos de grado medio y de grado superior al servicio de la Administración local del País Vasco, a los técnicos de grado medio de la Administración local gallega (5) y a la peculiar

(5) Asociación de Arquitectos e Ingenieros Técnicos de Grado Superior al Servicio de las Corporaciones Locales de Alicante, Castellón de la Plana y Valencia ( $B O E 4$ de enero de 1978); Asociación Sindical de Aparejadores, Arquitectos Técnicos, Ingenieros 
concepción del espacio regional, o al menos interprovincial, aportada por la coexistencia, en la Asociación de Funcionarios del Cuerpo Técnico de Delineantes de la Administración Local, de funcionarios locales de las Regiones gallega y asturiana, Provincias leonesas de Zamora y Salamanca, Provincias castellanas de Valladolid y Palencia y la Provincia de Logroño, esta última como área territorial provincial aspirante a la consecución de autonomía (6).

Una observación final merecen las asociaciones sindicales constituidas a nivel regional: la falta de infraestructura local y provincial en el Sindicato Unitario de la Región Andaluza y, en contraposición, la más sólida base local poseída por la Federación de Sindicatos Asturianos y la Unión de Funcionarios de Administración Local de Baleares, aspecto que relativiza, aún en mayor medida, la pobre representación regional de las asociaciones de funcionarios locales, porque si para las asociaciones sectoriales puede ser fácil su coordinación a nivel territorial, para las asociaciones sindicales generales la carencia de una precisa articulación local y provincial constituye un obstáculo que se puede considerar insuperable desde el punto de vista de la proyección funcional de la asociación. En este sentido la carencia de base asociativa local y provincial, en una Región territorialmente tan compleja como la andaluza, permite vaticinar al sindicato andaluz una existencia de dificultosa operatividad, reduciendo como consecuencia la muestra regional significativa de asociaciones sindicales de funcionarios locales a la federación asturiana.

Las referencias a las asociaciones locales y provinciales nos introduce en el tratamiento de las asociaciones sindicales constituidas . a ambos niveles, comenzando por reflejar las características que parecen particularizar al sindicalismo funcionarial de la Administración local en el nivel provincial.

\section{Asociaciones de ámbito provincial}

Las asociaciones de funcionarios locales constituidas con ámbito territorial provincial implican a las áreas provinciales que a continuación concretamos, sistematizadas por las circunscripciones geográficas que impone el mapa preautonómico:

Técnicos y Peritos al Servicio de las Corporaciones Locales de Alicante, Castellón y Valencia (BOE 28 de abril de 1978), y Asociación Gallega de Técnicos en Arquitectura e Ingeniería de la Administración Local (BOE 14 de junio de 1978).

(6) BOE 6 de enero de 1978. 
a) Región andaluza: Córdoba y Granada (7).

b) Región castellano-leonesa: Burgos, León, Palencia y Salamanca (8).

c) Región castellano-manchega: Albacete, Ciudad Real, Guadalajara y Toledo (9).

d) Región catalana: Barcelona y Gerona (10).

e) Región extremeña: Badajoz y Cáceres (11).

f) Región gallega: Lugo y Pontevedra (12).

g) Región valenciana: Alicante, Castellón y Valencia (13).

h) Región vasca: Guipúzcoa (14).

El cuadro transcrito permite apreciar la débil implantación del asociacionismo funcionarial en Andalucía, justificando las reservas expresadas en el punto precedente sobre el Sindicato Unitario de Funcionarios de la Región Andaluza. Asimismo facilita, con cierto grafismo, la observación de que sólo dos áreas regionales pluriprovinciales tienen constituidas asociaciones sindicales en todas sus Provincias, siendo especialmente sensible la falta de receptivi-

(7) Sindicato de Trabajadores y Funcionarios de la Administración Local de la Provincia de Córdoba (BOE 9 de junio de 1978) y Sindicato Unitario de Funcionarios de Administración Local (SUFAL) (Granada) (BOE 26 de noviembre de 1977).

(8) Sindicato Provincial de Funcionarios y Trabajadores de la Administración Local de Burgos (BOE 16 de junio de 1978), Asociación Profesional de Funcionarios de la Administración Local de la Provincia de León (APROFAL) (BOE 2 de junio de 1979), Sindicato de Funcionarios de la Administración Local de Palencia (BOE 10 de octubre de 1977) y Asociación Sindical de Funcionarios de la Administración Local de la Provincia de Salamanca (BOE 5 de mayo de 1979).

(9) Sindicato de Trabajadores de la Administración Local de la Provincia de Albacete (BOE 16 de marzo de 1978), Sindicato Independiente de Funcionarios de la Provincia de Toledo (BOE 8 de mayo de 1978), Asociación Sindical Independiente de Funcionarios de la Administración Local de la Provincia de Ciudad Real (ASIFAL) (BOE 16 de junio de 1978) y Sindicato Independiente de Funcionarios de la Administración Local de la Provincia de Guadalajara (BOE 2 de junio de 1979).

(10) Sindicato Independiente de Funcionarios, Empleados y Trabajadores de la Administración Local de la Provincia de Barcelona (BOE 23 de noviembre de 1978) y Sindicato de Trabajadores de Administración Local de la Provincia de Gerona (SINPAL) (BOE 3 de junio de 1978).

(11) Asociación Sindical Provincial de Funcionarios de la Administración Local (Badajoz) (BOE 24 de enero de 1978) y Asociación Profesional de Funcionarios de la Administración Local de la Provincia de Cáceres no integrados en los actuales Cuerpos Nacionales (BOE 10 de abril de 1978).

(12) Sindicato de Funcionarios de la Administración Local de la Provincia de Lugo (BOE 23 de mayo de 1978) y Sindicato de Funcionarios de la Administración Local de la Provincia de Pontevedra (BOE 1 de julio de 1978).

(13) Federación de Sindicatos de la Administración Local de la Provincia de Alicante (FASALEA) (BOE 16 de marzo de 1978), Asociación Profesional Independiente de Funcionarios de Administración Local de Castellón (BOE 26 de junio de 1978) y Sindicato Independiente de Funcionarios de la Administración Local de Valencia (BOE 6 de noviembre de 1978).

(14) Sindicato de Trabajadores de la Administración Local de Guipúzcoa (STALGUI) (BOE 15 de junio de 1978). 
dad a estas asociaciones en el País Vasco, como complemento al caso andaluz. También es llamativa la inexistencia de asociaciones provinciales en Aragón y Canarias, como Regiones integradoras de varias Provincias, ya que la existencia de asociaciones sindicales de ámbito provincial en Logroño-Rioja, Murcia o Santander-Cantabria elevaría a regionales las aún inexistentes asociaciones de las Provincias-Regiones mencionadas, situación de la que únicamente se marginaría la actual Provincia de León, de confirmarse su separación del ente preautonómico castellano-leonés.

La dinámica de las asociaciones profesionales recibe, en alguna medida, impulso de las asociaciones que tienen como base subjetiva los funcionarios que prestan sus servicios a Diputaciones provinciales, asociaciones que se sitúan, como ya significábamos en la introducción, a medio camino entre las asociaciones locales, por su vinculación al centro administrativo en que radica la Diputación provincial, y su adaptación al ámbito provincial, como consecuencia de la pluralidad de servicios de las Diputaciones en distintos y diversos puntos de la respectiva Provincia, circunstancia que, de facto, contribuye a provincializar a las asociaciones sindicales que integran a los funcionarios de las Diputaciones provinciales. Siguiendo este último criterio, la muestra de asociacionismo provincial, encontraría, para las áreas regionales con menor dinamismo asociativo, los puntos de referencia complementarios de Huelva, en Andalucía (15); Segovia, en Castilla-León (16), y Orense, en Galicia (17), y las Asociaciones de Funcionarios de las Diputaciones Provinciales de Huesca (18) y Santa Cruz de Tenerife (19) aportarían la primera muestra de un peculiar asociacionismo provincial a los entes preautonómicos aragonés y canario. No obstante, y aun forzando el carácter provincial de las asociaciones constituidas a nivel de Diputaciones, se logra superar el resultado de ser sólo dos las Regiones pluriprovinciales-Extremadura y País Valencianoque llegan a cubrir el respectivo mapa provincial.

(15) Sindicato de Funcionarios de la Excelentísima Diputación Provincial de Huelva (BOE 29 de marzo de 1978).

(16) Asociación Sindical de la Excelentísima Diputación Provincial de Segovia (BOE 26 de abril de 1978).

(17) Asociación de Funcionarios de la Diputación Provincial de Orense (BOE 12 de marzo de 1979).

(18) Asociación de Funcionarios de la Excelentísima Diputación Provincial de Huesca (BOE 8 de septiembre de 1978).

(19) Sindicato de Funcionarios de la Administración Local de la Excelentísima Mancomunidad Provincial Interinsular de Santa Cruz de Tenerife (BOE 28 de mayo de 1979). 
En referencia a las asociaciones provinciales sectoriales, se constata su pequeña entidad con dos asociaciones constituidas: la Asociación Sindical de Aparejadores y Arquitectos Técnicos al Servicio de la Administración Local, con ámbito territorial de referencia en la Provincia de Madrid (20) y cuyo ámbito subjetivo es, paradójicamente, disputado por el segundo ente asociativo constituido: la Asociación Sindical de Arquitectos e Ingenieros Técnicos al Servicio de las Corporaciones Locales de la Provincia de Madrid (21).

Volviendo a dar por válido el carácter provincial de las asociaciones sectoriales de funcionarios vinculadas a Diputaciones provinciales, sólo es posible constatar la importancia relativa que adquiere el asociacionismo sectorial en Madrid (22), en coexistencia con la Asociación de Funcionarios del Departamento Técnico de la Diputación Provincial de Oviedo (FUTEC) (23), y que, en referencia a esta última asociación, no hace sino corroborar, como apreciaremos en otro punto, el perfilado modelo asociativo de los funcionarios de la Administración local de la Región asturiana.

\section{Asociaciones de Ámbito comarcal}

Las asociaciones de funcionarios de Administración local nos aportan la sorpresa de presentar la unidad comarcal como núcleo aglutinante territorial, ofreciendo una muestra de valoración de la Comarca como unidad territorial, que contrasta con la relegación o utilización incoherente por la Administración central de la Comarca en su calidad de unidad de acción administrativa (24). Sin embargo, no es posible ignorar que la operatividad de las asociaciones comarcales se limita a las seis asociaciones de este carácter constituidas en la Provincia de Alicante (25) que, sin duda,

(20) BOE 15 de julio de 1978.

(21) BOE 27 de mayo de 1978.

(22) Asociación de Funcionarios Técnicos de Administración General de la Diputación Provincial de Madrid (BOE 12 de marzo de 1979), Asociación de Funcionarios de Servicios Especiales del Parque Móvil de la Diputación Provincial de Madrid (BOE 12 de marzo de 1979) y Asociación Sindical de Arquitectos e Ingenieros de la Excelentísima Diputación Provincial de Madrid (BOE 27 de febrero de 1979).

(23) BOE 12 de septiembre de 1978.

(24) Vid. autores y datos utilizados en mi trabajo «La Comarca como factor de coherencia regional», en el núm. 202 (1979) de esta RevisTA, págs. 197-232.

(25) Asociación Sindical de Funcionarios de la Administración Local de Callosa de Segura (Alicante) y Comarca (BOE 28 de noviembre de 1977), Asociación Sindical de Funcionarios Trabajadores de la Administración Local de la Ciudad de Villena (Alicante) y Comarca (ASFAL) (BOE 9 de febrero de 1978), Sindicato de Trabajadores del Ayuntamiento de Alcoy y Comarca (BOE 3 de marzo de 1978), Sindicato de 
constituyen un modelo insólito de coherencia en la articulación de las asociaciones sindicales de funcionarios de la Administración local, modelo que se diría influido por las posiciones doctrinales que han visto en la comarcalización parte importante de las soluciones a la problemática de las áreas no urbanas (26). Al margen de las asociaciones comarcales alicantinas, sólo son citables, a nivel de asociaciones generales, dos asociaciones, en Oviedo y Valencia, que implican, de hecho, a dos áreas comarcales, pero sin mención expresa a la idea de Comarca y, en el caso de la asociación valenciana, toma como insólita referencia, según el texto del anuncio del Servicio de Asuntos Sindicales, el "Partido judicial de Gandía y tres pueblos más», desliz que suponemos imputable a los funcionarios encargados del Servicio. Como posible complemento, sólo cabe plantear la asimilación a la unidad comarcal de la división jurisdiccional de partido judicial, como criterio seguido en la constitución de los sindicatos de funcionarios de Mieres, Lena y Luarca (27).

En el terreno de las asociaciones sectoriales con ámbito comarcal, únicamente se registra la existencia de la Asociación de Funcionarios Locales al Servicio de Extinción de Incendios, con proyección territorial sobre la isla de Mallorca (28), peculiaridad insular de la que se puede extraer el paralelismo Isla-Comarca, pero en la que los factores voluntaristas propios de la unidad comarcal, en su calidad de unidad que tiene que vencer la resistencia de los

Funcionarios de Administración Local de la Villa de Crevillente y Comarca (Alicante) (BOE 14 de abril de 1978), Sindicato de Trabajadores de la Administración Local de la Marina Baja (Alicante) (BOE 3 de marzo de 1978) y Sindicato de Trabajadores de la Administración Local de la Marina Baja (Alicante) (BOE 24 de abril de 1978).

(26) Como aportaciones más significativas, vid. MARTín MATEO: la Comarcalización de los pequeños Municipios, Secretaría General Técnica del Ministerio de la Gobernación, Madrid, 1964, en especial págs. 11-12; MoRell OCAÑa: «La Comarca como área administrativa infraprovincial», Documentación Administrativa, núm. 111 (1977), páginas 16 y 21 , y «La nueva Ley de Régimen Local II. La Supramunicipalidad», Revista Española de Derecho Administrativo, núm. 9 (1976), págs. 249-253 y 262-267; MeILÁN GIL: Problemática actual de las Administraciones públicas, III Jornadas Administrativas de Galicia, Escuela Nacional de la Administración Pública, Madrid, 1979, página 101.

(27) Sindicato de Trabajadores de la Administración Local de la SAFOR (Gandía y tres pueblos más) (BOE 11 de junio de 1978), Sindicato de Funcionarios de los Ayuntamientos de Belmonte, Candano, Grado, Las Requeras, Salas y Somiedo (CUNAPI) (BOE 14 de agosto de 1978), Sindicato de Funcionarios del Ayuntamiento de Mieres (BOE 7 de noviembre de 1977), Sindicato de Funcionarios de la Administración Local del Ilustrísimo Ayuntamiento de Lena (Oviedo) (SFALAL) (BOE 18 de noviembre de 1978) y Sindicato de Funcionarios de Luarca (Oviedo) (SFALL) (BOE 21 de noviembre de 1977).

(28) BOE 17 de enero de 1978. 
habituales límites locales y provinciales, no es constatable, de modo tan nítido al menos, como en las asociaciones sindicales de Alicante.

\section{ASOCLACIONES DE ÁMBITO LOCAL}

Las asociaciones de funcionarios de Corporaciones locales constituidas con ámbito territorial local presentan, a nivel de asociaciones de carácter general, la peculiaridad de estar polarizadas en Asturias, Canarias, Cataluña y País Valenciano, sin perjuicio de las peculiaridades geográficas y administrativas que concurren en las Plazas de Ceuta y Melilla, cuyas asociaciones pueden ser equiparadas a asociaciones de ámbito local (29).

El mayor número de asociaciones corresponde a Asturias, con diecisiete asociaciones sindicales constituidas (30), seguida del País Valenciano, con siete, de las que cinco radican en la Provincia de Alicante (31); Cataluña, con seis, de las que cinco están constitui-

(29) Asociación de Funcionarios del Ayuntamiento de Ceuta no pertenecientes a Cuerpos Nacionales (BOE 3 de abril de 1979) y Asociación de Funcionarios del Excelentísimo Ayuntamiento de Melilla (BOE 12 de enero de 1978).

(30) Asociación Sindical de Funcionarios de la Administración Local de Aller (Oviedo) (BOE 30 de enero de 1978); Sindicato de Funcionarios de la Administración Local de Avilés (SFALA) (BOE 17 de septiembre de 1977); Sindicato de Trabajadores de la Administración Local de Cangas de Narcea (Oviedo) (BOE 2 de diciembre de 1977); Sindicato de Funcionarios Locales de Carreño (SINFALCA) (BOE 7 de diciembre de 1977); Sindicato de Trabajadores de Administración Local de Castrillón (Oviedo) (BOE 6 de octubre de 1977); Sindicato de Trabajadores de Administración Local (SINTAL) de Gijón (BOE 7 de noviembre de 1977); Sindicato de Trabajadores de la Administración Local de Gozón (Luanco) (Oviedo) (BOE 21 de noviembre de 1977); Sindicato de Funcionarios de la Administración Local de Langreo (SFALL) (Oviedo) (BOE 26 de noviembre de 1977); Sindicato de Funcionarios de la Administración Local de Laviana (Oviedo) (STALLA) (BOE 14 de noviembre de 1977); Sindicato de Funcionarios de la Administración Local del Ayuntamiento de Lena (Oviedo) (BOE 17 de noviembre de 1977); Sindicato de Funcionarios de la Administración Local de Luarca (SFAAL) (Oviedo) (BOE 21 de noviembre de 1977); Sindicato de Funcionarios del Ayuntamiento de Mieres (Oviedo) (BOE 17 de noviembre de 1977); Sindicato de Trabajadores del Ayuntamiento de Oviedo (BOE 22 de noviembre de 1977); Sindicato de Funcionarios de la Administración Local de Pravia (Oviedo) (SFALPRA) (BOE 9 de diciembre de 1978); Sindicato de Trabajadores de la Administración Local de Ribadesella (Oviedo) (BOE 10 de junio de 1978); Sindicato de Trabajadores de la Administración Local de San Martín del Rey Aurelio (Oviedo) (STALSMRA) (BOE 8 de noviembre de 1977), y Sindicato de Trabajadores de la Administración Local de Siero (Oviedo) (BOE 25 de octubre de 1977).

(31) Sindicato de Funcionarios de la Administración Local del Ayuntamiento de Alicante (BOE 26 de noviembre de 1977); Sindicato de Trabajadores de la Administración Local de Benidorm (Alicante) (BOE 27 de febrero de 1978); Sindicato de Trabajadores del Ayuntamiento de Elche (Alicante) (STAE) (BOE 15 de mayo de 1978); Sindicato de Trabajadores de la Administración Local del Ayuntamiento de Monóvar (Alicante) (STALM) (BOE 11 de abril de 1978), y Sindicato Local de Funcionarios y Trabajadores de la Administración Local del Ayuntamiento de Petrel (Alicante) (BOE 
das en la Provincia de Barcelona (32), y, finalmente, Canarias, con cuatro asociaciones (33). Al margen de las comunidades autónomas y entes preautonómicos referidos, sólo son citables la constitución en el País Vasco de la Asociación Sindical de Trabajadores del Ayuntamiento de Bilbao ( $B O E 10$ de enero de 1979) y la articulación en el Ayuntamiento de Madrid de su Unión de Asociaciones de Funcionarios (BOE 25 de enero de 1979).

Sin ánimo de ser prolijos, sí se puede estimar oportuno haber concretado el número de asociaciones constituidas por áreas regionales, con la finalidad de visualizar la dinámica asociativa de los funcionarios locales en sólo cinco Regiones y, de este modo, mostrar el contraste existente con el resto de las Regiones que no cuentan con asociaciones locales: Andalucía, Aragón, Baleares, Cantabria, Castilla-León, Castilla-La Mancha, Extremadura, Galicia, Murcia y Rioja.

Las asociaciones sectoriales no permiten establecer correcciones sustanciales: las once asociaciones sectoriales que hemos individualizado están orientadas por el criterio de una notable especialización en sus componentes subjetivos, y poseen la peculiaridad de tomar como referencia exclusiva a los funcionarios de Administración local de Madrid (34) y Zaragoza (35), a salvo de la

9 de mayo de 1978). En Castellón está constituido el Sindicato de Funcionarios de la Administración Local del Ayuntamiento de Burriana (BOE 13 de julio de 1978), y en Valencia el Sindicato Independiente de Funcionarios de Carrera y de Empleo del Ayuntamiento de Alcira (BOE 1 de julio de 1978).

(32) Asociación de Funcionarios de Administración Local y Personal Contratado de Granollers (Barcelona) (BOE 1 de octubre de 1977); Asociación de Funcionarios de la Administración Local de Mollet (Barcelona) (BOE 24 de enero de 1978); Asociación de Funcionarios de Administración Local de Montornés del Vallés (Barcelona) (BOE 27 de febrero de 1979); Asociación de Funcionarios Públicos y Personal Contratado del Excelentísimo Ayuntamiento de Reus (BOE 28 de diciembre de 1978), y Asociación de Funcionarios de Administración Local y Personal Contratado Administrativamente de Ripollet (BOE 1 de junio de 1978). En Tarragona está constituida la Asociación de Empleados del Ayuntamiento de Cambrills (BOE 14 de mayo de 1979).

(33) Asociación Profesional Sindical de Funcionarios de Administración Local de Las Palmas de Gran Canaria (BOE 6 de septiembre de 1977); Sindicato de Funcionarios del Ilustre Ayuntamiento del Rosario (Santa Cruz de Tenerife) ( $B O E 30$ de junio de 1979); Sindicato de Funcionarios del Ayuntamiento de San Miguel (Tenerife) (BOE 15 de octubre de 1979), y Asociación Profesional de Funcionarios de Administración Local del Ayuntamiento de Santa Cruz de Tenerife (BOE 15 de mayo de 1979).

(34) Asociación Profesional Sindical de Funcionarios de Servicio de Asistencia Interna y Ceremonial del Ayuntamiento de Madrid (BOE 26 de noviembre de 1977); Asociación Sindical de Funcionarios de los Servicios Técnicos Municipales de Madrid (FUSAL) (BOE 21 de enero de 1978); Asociación Sindical Profesional de Funcionarios del Subgrupo Administrativo del Ayuntamiento de Madrid (BOE 22 de diciembre de 1977); Asociación de Técnicos de Administración General y Técnicos Administra. tivos del Ayuntamiento de Madrid (BOE 24 de diciembre de 1977); Asociación Profesional Sindical de Funcionarios del Servicio de Talleres Generales y Parque Móvil 
Asociación de Funcionarios de la Administración General y Técnicos de Administración del Ayuntamiento de Almería (BOE 30 de enero de 1979).

Con ello se puede llegar a la conclusión del reducido relieve del fenómeno asociativo sindical en los funcionarios de las Corporaciones locales, a salvo de la mayor dinámica asociativa registrable en Asturias y Alicante, a cuyas asociaciones locales es preciso incorporar los Ayuntamientos implicados en asociaciones comarcales. Sin embargo, al margen de estas dos referencias, es excesivo el contraste de las asociaciones constituidas y las áreas territoriales que implican, con las áreas territoriales sin asociaciones y con el crecido número de Ayuntamientos existentes, cuyos funcionarios ofrecen la apariencia de poder obviar la necesidad de constituir asociaciones sindicales como medio de defensa de sus intereses profesionales con referencia en la respectiva Corporación local.

\section{EL AMBITO SUBJETIVO CUBIERTO \\ POR LAS ASOCIACIONES SINDICALES DE FUNCIONARIOS DE LA ADMINISTRACION LOCAL. EL CONTRASTE ENTRE LA REGULACION NORMATIVA Y LA PRACTICA ASOCIATIVA}

Los componentes subjetivos que pueden integrar las asociaciones sindicales de funcionarios están delimitados, con precisión, en el artículo $10^{\circ}$ del Real Decreto 1522/1977, de 17 de junio: funcionarios públicos y personal contratado en régimen de Derecho administrativo. Ante estos dos puntos delimitadores, sólo es posible

del Excelentísimo Ayuntamiento de Madrid (BOE 20 de mayo de 1978); Asociación Sindical del Subgrupo de Auxiliares del Ayuntamiento de Madrid (BOE 6 de junio de 1978), y Asociación Profesional Sindical de Funcionarios del Servicio de Colegios Nacionales e Instituciones Escolares del Ayuntamiento de Madrid (BOE 26 de junio de 1978). Observemos, según dato aportado en páginas precedentes, que las asociaciones sectoriales constituidas en el Ayuntamiento de Madrid están integradas en la Unión de Asociaciones de Funcionarios del Ayuntamiento de Madrid (BOE 25 de enero de 1979).

(35) Asociación Profesional Sindical de Funcionarios Licenciados en Derecho al Servicio del Excelentísimo Ayuntamiento de Zaragoza (BOE 17 de junio de 1978); Asociación Sindical Profesional de Técnicos de Grado Superior y Medio del Ayuntamiento de Zaragoza (BOE 20 de junio de 1978), y Asociación Profesional Sindical de Funcionarios del Subgrupo de Administrativos y Auxiliares de Administración General y Otros Funcionarios de los Mismos Niveles 4 y 6 al Servicio del Excelentísimo Ayuntamiento de Zaragoza (BOE 20 de marzo de 1979). 
considerar la tipología que, con arreglo a la Ley de Funcionarios Civiles del Estado, comprende el concepto de funcionario público: funcionarios de carrera y funcionarios de empleo; estos últimos, con las subcategorías de funcionarios eventuales y funcionarios interinos (36), esquema asimilado para las Corporaciones locales por el texto articulado parcial de la Ley de Bases del Estatuto de Régimen Local de 1975 (37). El ámbito delimitado por ambos textos normativos recibe el matiz de las exclusiones que determina el artículo 3..$^{\circ}$ del Real Decreto: personal y funcionarios adscritos a los servicios de seguridad, instituciones penitenciarias $\mathrm{y}$, en general, el personal y funcionarios cualificados por el uso de armas $\mathrm{y}$, finalmente, la previsión del párrafo $2 .^{\circ}$ del artículo $1 .^{\circ}$, que determina la suspensión temporal en las organizaciones profesionales de los afiliados en los que concurra la circunstancia de funcionarios de carrera en situación de excedencia especial, en los casos de nombramiento por Decreto para cargo político o de confianza de carácter no permanente.

La mayor parte de las asociaciones constituidas respetan este planteamiento y tipifican sus componentes subjetivos en base a la posesión de las condiciones de funcionario de carrera, interinos y contratados en régimen de Derecho administrativo, pudiéndose observar la relegación de las categorías de funcionarios eventuales, en lógica coherencia con las peculiaridades y escaso significado numérico que esta categoría funcionarial posee. Sin embargo, en contraste con esta clara delimitación del ámbito subjetivo a cubrir por las asociaciones sindicales, se observa el uso, en la denominación de un número no desdeñable de asociaciones, del término «trabajadores», como sustitutivo del término funcionarios, concurriendo la circunstancia de que la sustitución no es producto de preferencias semánticas, sin contenido conceptual, sino que, por el contrario, tiene adecuada correspondencia en la particularización del ámbito subjetivo de las asociaciones que utilizan tal término y que, como muestra de la reflexiva acogida del vocablo, suelen utilizar, de modo simultáneo, el término de "sindicato» para denominar a la asociación. A mayor abundamiento, la mayor parte de estas asociaciones sindicales, al concretar el ámbito profesional, según término acuñado por el Servicio de Asuntos Sindicales, dan entrada a «todos los trabajadores de la Administración local» o

(36) Artículos 3-5 del Real Decreto 315/1964, de 17 de febrero.

(37) Artículos 23-25 del Real Decreto 3046/1977, de 6 de octubre. 
a «los trabajadores de la Administración local» el correspondiente ámbito territorial en el que opera la respectiva asociación o sindicato. Este es el caso de los denominados «Sindicatos de Trabajadores de la Administración Local» en Castrillón, Siero, Gozón (Luanco), Monóvar y Guipúzcoa y de la Asociación Sindical de Trabajadores del Ayuntamiento de Bilbao (38). En otros casos, con menor radicalismo, se superponen las ideas de funcionarios y trabajador, o bien se utiliza la técnica de unión copulativa o disyuntiva: caso del Sindicato Provincial de Trabajadores Funcionarios de Administración Local de Burgos (39), del Sindicato Local de Funcionarios y Trabajadores de Administración Local del Ayuntamiento de Petrel (40) y de la Federación de Sindicatos de Administración Local de la Provincia de Alicante, en cuyo seno pueden integrarse «los sindicatos, asociaciones $u$ organizaciones de funcionarios o trabajadores de la Administración local de la Provincia» (41). Con la finalidad de completar la referencia, es significativo el caso del Sindicato Independiente de Funcionarios, Empleados y Trabajadores de la Administración Local de la Provincia de Barcelona (42), que ofrece la impresión de saber y querer diferenciar, de modo muy nítido, las tres categorías conceptuales que utiliza en su denominación. Tratando de agotar la fenomenología que provoca la interferencia del término «trabajador» en el ámbito subjetivo de algunas asociaciones sindicales de funcionarios locales, cabe recoger el caso de las entidades asociativas en las que, bien en la denominación o bien en la delimitación del ámbito subjetivo, conceden entrada al término «trabajadores» de la Administración local o al más ambiguo de "personal». En esta situación se encuentran el Sindicato de Funcionarios de Administración Local de Langreo (SFALL), que delimita sus componentes subjetivos desde la idea de «personal de la Administración local del Municipio de Lan-

(38) Sindicato de Trabajadores de la Administración Local de Castrillón (BOE 6 de octubre de 1977); Sindicato de Trabajadores de la Administración Local de Siero (BOE 25 de octubre de 1977); Sindicato de Trabajadores de la Administración Local de Gozón (Luanco) (BOE 21 de noviembre de 1977); Sindicato de Trabajadores de Administración Local del Ayuntamiento de Monovar (BOE 11 de abril de 1978); Sindicato de Trabajadores de la Administración Local de Guipúzcoa (STALGUI) (BOE 15 de junio de 1978), y Asociación Sindical de Trabajadores del Ayuntamiento de Bilbao (BOE 10 de enero de 1979).

(39) BOE 16 de junio de 1978.

(40) BOE 9 de mayo de 1978.

(41) BOE 10 de abril de 1978.

(42) BOE 28 de noviembre de 1978. 
greo» (43); el Sindicato de Funcionarios de la Administración Local del Ayuntamiento de Alicante, que concede entrada al "personal que preste un servicio y reciba un sueldo o salario del citado Ayuntamiento de Alicante» (44); el Sindicato de Funcionarios de Administración Local de Carreño, cuyo ámbito subjetivo se centra en los «trabajadores de la Administración local de Carreño» (45), o el más complicado caso de la Asociación Sindical de Funcionarios de la Diputación Provincial de Santander, proyectada sobre «todos los empleados, funcionarios, laborales, contratados, cualquiera que sea su situación administrativa» (46).

En todas las asociaciones sindicales que han sido citadas concurre la circunstancia de que el ámbito subjetivo delimitado por el Real Decreto regulador de las asociaciones sindicales de funcionarios públicos es interferido, si no superado, por la colusión de posibles asociados que, al tener formalizada su relación de servicios con la correspondiente Corporación local, bajo forma jurídica laboral, no se adecuan, en sentido estricto, a las categorías conceptuales que el texto articulado de la Ley de Funcionarios Civiles del Estado y el texto articulado parcial de la Ley de Bases del Estatuto de Régimen Local delimitan como propio de la relación funcionarial. Ello no obsta para que seamos conscientes de la progresiva y quizá necesaria superación de las diferencias jurídico-formales entre las distintas categorías de personas que prestan sus servicios a la Administración, problemática que encuentra su causa, entre otras, en la práctica administrativa suscitada por los mismos órganos de la Administración que han contribuido a difuminar el sentido $\mathrm{y}$ virtualidad de precisas normas jurídicas y que han propiciado la necesidad de buscar un nuevo marco de referencia en el que sean delimitadas nuevas categorías conceptuales para la función pública, planteamiento en el que ya se centran las preocupaciones de los responsables de los sucesivos anteproyectos de Ley de la Función Pública (47), que tendrán que ser considerados en el proyecto de Ley de Régimen Local y que, en último extremo, no son sino corolario de la inevitable aproximación de la normativa fun-

(43) BOE 26 de noviembre de 1978.

(44) BOE 26 de noviembre de 1978.

(45) BOE 7 de diciembre de 1977.

(46) BOE 9 de diciembre de 1977.

(47) Esta problemática la hago objeto de una más detenida consideración en mi precitado trabajo Las Asociaciones Sindicales de Funcionarios en la Administración Central, Institucional y Corporativa. 
cionarial y de la normativa laboral, como aspecto ya considerado por los profesores Parada Vazouez y Boquera Oliver (48).

Otras asociaciones que dan entrada en su denominación o ámbito subjetivo a los términos «trabajador», «personal» o «empleados» salvan la contraposición con el Real Decreto 1522/1977, como consecuencia de aludir, de modo expreso, a las limitaciones que establece la disposición mencionada. En esta circunstancia se halla el Sindicato de Trabajadores de la Administración Local de Benidorm, integrador de las "personas que presten cualquier servicio de manera permanente y perciban un sueldo de la Administración local de Benidorm", pero que inmediatamente delimita el amplio contenido que es predicable del párrafo transcrito, mediante la cláusula «sin más excepciones que las establecidas en el Real Decreto 1522/1977, de 17 de junio», referencia delimitadora tanto en sentido positivo como negativo (49). Problemática similar presenta el Sindicato de Trabajadores del Ayuntamiento de Alcoy, que considera como punto de referencia subjetivo a los «trabajadores del Ayuntamiento de Alcoy y Comarca», pero con la importante precisión de añadir de modo inmediato: «con las limitaciones que indica el Decreto 1522/1977, de 17 de junio" (50). En otras asociaciones, sin necesidad de referencia expresa al Real Decreto regulador, el problema suscitado por las denominaciones que incorporan el término «sindicato» o «trabajadores» se salva con facilidad por la nitidez con que delimitan su campo subjetivo: como ejemplo es citable el Sindicato de Trabajadores de la Administración Local de la Marina Baja (Alicante), cuyos posibles miembros se restringen a los «funcionarios» que presten sus servicios a las entidades locales implicadas (51). En igual situación se encuentra el

(48) Vid. Parada Vázoúz y los datos que aporta en relación con las reivindicaciones funcionariales de principios de siglo en Francia, en cuya base latía ya la idea de que los funcionarios eran unos trabajadores más y como tal querían ser tratados, así como sus consideraciones sobre la tendencia al encuentro de los trabajadores públicos y privados, reflejado en el grafismo de que los trabajadores y funcionarios llevan decenios «espiándose» "para exigir del Estado, árbitro y juez, al fin y a la postre, de unos y otros las ventajas del vecino" (PARADA VÁzQUEz: Sindicatos y asociaciones de funcionarios públicos, Madrid, 1968, págs. 26-27). En conexión con la misma problemática, BoQUERA OLIVER significa cómo los derechos y obligaciones de los obreros dependen ahora más de la ley de los reglamentos que de la voluntad de los patronos y no existen diferencias sustanciales entre trabajadores y funcionarios p⿺rblicos $y$, por consiguiente, no deben existir diferencias esenciales entre agrupaciones profesionales de los primeros y los segundos (BOQUERA OLIVER: Las asociaciones de funcionarios públicos, cit., pág. 493).

(49) BOE 27 de febrero de 1978.

(50) BOE 3 de marzo de 1978.

(51) BOE 3 de marzo de 1978. 
Sindicato de Trabajadores de la Administración Local de la SAFOR (Gandía y tres pueblos más), entidad delimitada por su concreción operativa a «funcionarios y personal contratado» (52).

La última de las asociaciones mencionadas nos permite entrar en otro tema conflictivo planteado en el punto concreto del ámbito subjetivo del sindicalismo funcionarial: la consideración, entre los posibles miembros de la asociación, de los «funcionarios y personal contratado al servicio de la Administración local y de sus organismos autónomos» (53). Sin duda, el mimetismo que las técnicas jurídicas e institucionales de la Administración central tienen sobre la Administración local están en la razón última de utilizar la categoría de organismo autónomo en el seno de la Administración local. Sin embargo, esta asimilación terminológica no hace sino traducir la problemática que para la actividad de las Corporaciones locales implica lo que, con más acertada terminología, recoge la Asociación de Funcionarios de Administración Local y Personal Contratado Administrativamente de Ripollet, al convocar a sus registros de asociados a los funcionarios o al personal incorporado a la Administración local «indirectamente, a través de empresas municipales y patronatos» (54), o, como otra manifestación de progresivo distanciamiento de los módulos organizativos clásicos de la Administración local, la pretensión de integrar a funcionarios, empleados y trabajadores «incluso de las mancomunidades y agrupaciones municipales forzosas", como objetivo a cubrir por el Sindicato Independiente de Funcionarios, Empleados y Trabajadores de la Administración Local de la Provincia de Barcelona (55). No se requieren especiales argumentos para significar que en el terreno de la organización directa mediata, en terminología de GARCíaTreviJano (56), se plantea a la Administración local una compleja problemática en el momento de definir el statu jurídico de sus servidores $\mathrm{o}$, con menos retórica y más contenido, de sus profesionales. Las tres asociaciones sindicales mencionadas no sólo ayudan a problematizar el ajuste de sus pretensiones organizatorias a una disposición normativa, sino que invitan a plantear el tema, más complejo y problemático, de la situación jurídica de los profesio-

(52) BOE 23 de noviembre de 1978.

(53) BOE 23 de noviembre de 1978.

(54) $B O E 1$ de junio de 1978.

(55) BOE 23 de noviembre de 1978.

(56) García TreviJano: Tratado de Derecho administrativo, II, Madrid, 1967, páginas 1097-1105. 
nales responsables de los servicios gestionados mediante técnicas organizativas distintas de la Administración directa.

En el tratamiento de la temática de los componentes subjetivos a los que van dirigidas las asociaciones sindicales de funcionarios locales constituidas, también se puede reseñar la tendencia de algunas asociaciones a incluir a los funcionarios jubilados entre sus posibles miembros (57), o a incluir, conjuntamente, a funcionarios jubilados y excedentes (58), tendencias que poseen el interés de incorporar a la problemática del asociacionismo funcionarial el tema, no minimizable, de las clases pasivas, necesitadas de un mayor equilibrio en la consideración del funcionario jubilado. En la misma línea es factible situar la problemática del excedente, y de modo especial en la Administración local, en la que la compartimentalización funcionarial que grava a los funcionarios no pertenecientes a Cuerpos Nacionales no permite, sin más, identificar excedencia y oportunidad personal, como situación que pudiera encontrar mayor generalidad en el ámbito de la Administración central.

Otra peculiaridad observable en las asociaciones sindicales constituidas y que puede ser considerada como efecto inducido de lo que hemos denominado compartimentalización funcionarial, se materializa en la reducida operatividad de la idea de cuerpo, que sólo parece estar parcialmente presente en la Asociación de Funcionarios del Cuerpo Técnico de Delineantes de la Administración

(57) Sindicato de Trabajadores del Ayuntamiento de Oviedo (BOE 22 de noviembre de 1977); Sindicato de Trabajadores de la Administración Local de Benidorm (BOE 27 de febrero de 1978); Sindicato Provincial de Funcionarios Trabajadores de Administración Local de Burgos (BOE 16 de junio de 1978); Sindicato de Funcionarios de la Administración Local (SFAL) del Ayuntamiento de Burriana (BOE 13 de junio de 1978), y Sindicato Provincial de Funcionarios de la Administración Local de Palencia (BOE 10 de octubre de 1979).

(58) Sindicato Unitario de Funcionarios de Administración Local (SUFAL) (Granada) (BOE 26 de noviembre de 1977); Sindicato de Trabajadores de la Administración Local de la Marina Baja (Alicante) (BOE 3 de marzo de 1978); Sindicato Local de Funcionarios y Trabajadores de Administración Local del Ayuntamiento de Petrel ( $B O E 9$ de mayo de 1978); Sindicato de Funcionarios Trabajadores de la Administración Local de la Provincia de Córdoba (BOE 9 de junio de 1978); Sindicato Unitario de Funcionarios de Administración Local (Región andaluza y ciudades de Ceuta y Melilla) (BOE 28 de mayo de 1979), y Sindicato Independiente de Funcionarios de Administración Local de la Provincia de Guadalajara (BOE 2 de junio de 1979). La Asociación Profesional de Funcionarios de la Administración Local de la Provincia de Cáceres (BOE 10 de abril de 1978) y la Asociación de Funcionarios de Servicios Especiales del Parque Móvil de la Diputación Provincial de Madrid (BOE 12 de marzo de 1979) sólo contemplan la posible integración de los excedentes junto a los funcionarios en activo, v la Asociación de Funcionarios Técnicos de Administración General de la Diputación Provincial de Madrid (BOE 12 de marzo de 1979) enumera a los supernumerarios, junto a activos, pasivos y excedentes, que no estén en situación de excedencia especial. 
Local (59) y en la Asociación Profesional Sindical de Funcionarios del Subgrupo de Administrativos y Auxiliares de Administración General y Otros Funcionarios de los Mismos Niveles 4 y 6 al Servicio del Excelentísimo Ayuntamiento de Zaragoza (60). Sin embargo, la primera de las asociaciones no pasa de considerar la idea de cuerpo como un aglutinante estimulador que puede contribuir al buen fin de sus actividades y objetivos, y la segunda, con su casuística referencia a niveles de remuneración, sólo conserva homologable con la idea de cuerpo un factor económico que ni tan siquiera es unívoco. La falta de operatividad de la idea o de mecanismos similares a los de cuerpo se corrobora, como ya significamos, por la amplia y generosa orientación del ámbito subjetivo de las asociaciones constituidas, en la que si se particularizan excepciones, es para reincidir en las ya previstas en el Real Decreto regulador (61), y sólo se registra una anecdótica exclusión en la Asociación de Funcionarios del Cuerpo Técnico de la Diputación Provincial de Oviedo, que de modo expreso declara la «exclusión de todo personal administrativo» (62).

Como punto final en el tratamiento de la problemática presente en el tema del ámbito subjetivo cubierto por las asociaciones de funcionarios locales, puede ser aportado el dato, no exento de factores patológicos, del Sindicato Unitario de Funcionarios de la Administración Local (Región andaluza y ciudades de Ceuta y Melilla), que pretende integrar, como componentes subjetivos, a los «funcionarios públicos, bien a nivel de afiliación individual o de sindicatos asociados» (63), planteamiento que supone la mezcla indiferenciada de la técnica de asociación individual y de la técnica asociativa de segundo grado, supuesto este último propio y exclusivo de las federaciones y confederaciones, conforme al tenor literal del artículo $2 .^{\circ}$ del Real Decreto regulador del derecho de asociación sindical de los funcionarios públicos.

(59) BOE 6 de enero de 1978.

(60) BOE 20 de marzo de 1979.

(61) Caso específico de funcionarios con uso de armas, expresamente excluidos del Sindicato Independiente de Funcionarios de Administración Local de Valencia (BOE 6 de noviembre de 1978) y Asociación de Funcionarios del Ayuntamiento de Ceuta (BOE 3 de abril de 1979). Asimismo en algunas de las asociaciones o sindicatos en los que se admite la integración de excedentes, se menciona la exclusión expresa de los excedentes especiales.

(62) BOE 12 de septiembre de 1978.

(63) $B O E 28$ de mayo de 1979. 


\section{APRECIACIONES FINALES}

La consideración de los distintos tipos de asociaciones sindicales de funcionarios constituidas en el ámbito de la Administración local y la débil implantación que muestran, permite apreciar que los funcionarios de las Corporaciones locales no se han entusiasmado por los horizontes profesionales, o simplemente reivindicativos, que les pudiera abrir la técnica o el instrumento de las asociaciones sindicales. Esta situación contrasta con las opiniones que estimaban que la prohibición de asociaciones sindicales en la función pública implicaba un fenómeno con dinámica propia y de costosa contención, que, en último extremo, no significaba más que una peculiaridad del precedente sistema político autoritario y que el cambio político significaría la regularización de esta realidad social, dejando prever una especie de incontenida floración sindical (64). Estas premoniciones no se han cumplido en las asociaciones sindicales de funcionarios de la Administración local, y en este sentido es muy claro el balance que permiten establecer las asociaciones constituidas. Se constata la inexistencia de asociaciones vinculadas a funcionarios pertenecientes a Cuerpos Nacionales de la Administración local, de los que sólo existe el reflejo de la Asociación Profesional de Secretarios Habilitados; se constata una pobre incidencia regional de las asociaciones constituidas, sin posible paralelismo de la dinámica asociativa funcionarial con el mapa preautonómico; es apreciable la inexistencia de numerosas Provin-

(64) Como apoyo doctrinal para muchas afirmaciones posteriores, ha sido objeto de frecuente cita el libro de PARADA VÁzouez y, en concreto, la utilización de textos que el propio PARADA ha matizado a tenor de la evolución posterior de la problemática funcionarial, como el que el derecho sindical de los funcionarios contribuye a «abrir una saludable brecha de libertad en el tradicional autoritarismo en la gestion pública» $\mathrm{o}$, con un enfoque funcional, la afirmación de que "para una reforma de la función pública sustancial y fundamentalmente social, el concurso sindical, el apoyo informativo y la fuerza política de las asociaciones profesionales de funcionarios ha de ser decisivo; una reforma al margen de éstos puede degenerar en simples arreglos formales tras los que subsisten más inalcanzables y lejanos aún todos los objetivos sociales». Vid. PARAdA VÁzoUEz: Sindicatos y asociaciones de funcionarios públicos, citado, págs. 25 y 26. Sobre los matices de PARADA me remito a su conferencia en la Delegación del Colegio Oficial de Arquitectos de Salamanca: «Control y disciplina de la actividad urbanística», en el ciclo Aspectos Fundamentales del Planeamiento Urbano. Participación ciudadana y control, celebrado en Salamanca en marzo de 1979. Conferencia en publicación. En paralelismo con la orientación de PARADA, vid. las consideraciones de BOQUERA Oliver sobre el derecho de asociación de los funcionarios como manifestación no sólo legítima, sino útil, y respecto de la cual una excesiva desconfianza fomenta las asociaciones clandestinas o fuerza a recubrir con apariencia de legalidad a agrupaciones que viven al margen de ellas. BOQUERA OLIVER: Las asociaciones de funcionarios, cit., pág. 496. 
cias carentes de asociaciones sindicales provinciales, y, a salvo de la Región asturiana, de la Provincia de Alicante y del Ayuntamiento de Madrid, las asociaciones locales a nivel general o sectorial carecen de incidencia y significación.

Estos resultados son, sin duda, inesperados, no sólo por su contraste con las preconsideradas expectativas teóricas, sino por las consecuencias que pudieran derivar de acontecimientos concurrentes con la gestación del asociacionismo de los funcionarios locales: en particular, la mencionada disolución de los Colegios de Funcionarios Locales no pertenecientes a Cuerpos Nacionales, medida que desarticuló la estructura corporativa provincial y nacional de estos funcionarios (65), sin olvidar la problemática suscitada por las consecuencias que la conformación de la Administración regional tiene para la actual estructura organizativa de la Administración local, así como los incentivos aportados por la renovación política de las Corporaciones locales y el paralelo incremento de las competencias administrativas a desempeñar por la Administración local. En contraste con estos datos, que, en principio, deberían haber actuado como catalizadores que dinamizaran y fortalecieran las asociaciones sindicales de funcionarios de la Administración local, éstos sólo ofrecen el síntoma de una débil reacción que, con mucha lentitud, puede llegar a concluir en la organización de una estructura asociativa que, con base en asociaciones provinciales integradas en una asociación estatal, contribuya a reconstruir el desaparecido entramado orgánico de los Colegios disueltos.

No obstante, y a pesar de las circunstancias que pudieran propiciar una mayor receptividad de los funcionarios locales a sus asociaciones sindicales, la falta de acogida de éstas entre los funcionarios encuentra explicación en factores que neutralizan las aludidas circunstancias que parecían actuar como estímulos en el fomento del asociacionismo funcionarial. Entre estos factores puede ser considerado el relativo a la solución del conflictivo problema de los funcionarios contratados e interinos, en fecha casi concurrente con la publicación del Real Decreto regulador de las asociaciones sindicales de funcionarios (66), problema que sustituyó las tensiones existentes en muchas Corporaciones locales por una si-

(65) Sobre el tema, mi trabajo «Implicaciones de la disolución de los Colegios de funcionarios locales», Revista Española de Derecho Administrativo, núm. 21 (1979), páginas 241-252.

(66) Decreto núm. 1409/1977, de 2 de junio, y Orden ministerial de 8 de noviembre de 1977. 
tuación mucho más distendida y poco propicia, al menos transitoriamente, al planteamiento de conflictos. Otra causa que contribuye a desincentivar la constitución de entidades asociativas se materializa en la compartimentalización administrativa, que, a salvo de los funcionarios de Cuerpos Nacionales, afecta al resto de los funcionarios de cada Corporación local, fenómeno que determina que la actividad asociativa encuentre dificultades en su articulación, cuando entre entidades locales limítrofes no es posible el traslado de funcionarios y existen rasgos diferenciadores notables en función de las peculiaridades de cada Corporación local. A esta compartimentalización en materia funcionarial se añade la heterogénea amalgama de profesionales que se integra en cada Corporación y entre los que la comunidad de intereses no es fácil de individualizar, cuando sus funciones, remuneraciones y posibilidades de acción profesional son muy diversas entre los distintos y, en ocasiones, pequeños grupos de funcionarios, y la posibilidad de integrar a los profesionales de distintas Corporaciones está obstaculizada por el carácter de funcionarios propios de una Corporación, con una situación, a término, en la que también se mezclan factores diferenciadores entre las distintas entidades locales, que hace difícil la constitución de asociaciones sindicales sectoriales que puedan desarrollar una labor coherente a nivel provincial o nacional. Más acusada es la dificultad de conseguir una efectiva proyección funcional en los intereses que puedan representar en las asociaciones de carácter general de amplia base territorial, como consecuencia de que sus componentes subjetivos se conciben con la amplitud indiscriminada que implica el permitir la integración de funcionarios de carrera, empleo y contratados en régimen de Derecho administrativo, amplitud de la que es reflejo la frecuente utilización en la denominación de las asociaciones del término "trabajadores», como categoría omnicomprensiva, ambigua y que parece preocupada con la homologación de las tradicionales organizaciones sindicales y que, a efectos operativos, encuentra, con facilidad, el obstáculo de definir el sentido de su orientación, como efecto derivado de la fácil neutralización de los distintos y heterogéneos intereses entre los distintos y heterogéneos grupos que se pueden integrar en estas entidades asociativas generales.

Como consecuencia de la problemática descrita, encuentra posible explicación el reducido número de asociaciones sectoriales constituidas a nivel nacional, regional o provincial, y la localización, 
prácticamente en exclusiva, de las asociaciones sectoriales en el Ayuntamiento de Madrid, como Corporación local de notable complejidad, en la que los grupos de funcionarios especializados implican a colectivos con cierta entidad. La observación es válida, aunque con diferencias cuantitativas, para las asociaciones sectoriales constituidas en el Ayuntamiento de Zaragoza y para las asociaciones sectoriales regionales operantes en el País Valenciano. En contraste, no puede pasar inadvertido el preguntarnos sobre la falta de entidades asociativas sectoriales en Ayuntamientos como los de Barcelona, Bilbao o Sevilla, de tanta o más complejidad que los preconsiderados, y en los que, como en tantas otras Corporaciones locales, no hay muestras de asociacionismo sindical en sus funcionarios.

A las causas mencionadas se une el dato, tampoco minimizable, de la debilidad crónica, mejor postración, que particulariza a las Corporaciones locales a nivel económico y que prácticamente anula la dinámica sindical de los funcionarios $\mathrm{y}$, en consecuencia, de las asociaciones sindicales que puedan integrarlos, en cierto paralelismo con la dificultosa operatividad sindical de las empresas privadas en crisis, pero con consecuencias sociales más graves, en tanto la seguridad en el puesto de trabajo que posee el funcionario público le permite márgenes de maniobra en alguna medida compensatorios de la injusta situación retributiva o de las condiciones de trabajo en que pueda encontrarse, $y$, de este modo, la salida de autodefensa concretada en una menor dedicación profesional o en la flexible interpretación de las incompatibilidades profesionales..., puede llegar a configurarse como una técnica autocompensadora, pero con consecuencias imprevisibles para el correcto cumplimiento de las funciones públicas. Sólo con apoyo en esta peligrosa técnica de la autocompensación parece encontrar explicación la falta de reacción funcionarial a la supresión de los Colegios de funcionarios locales y el desinterés por regenerar, con base en el asociacionismo voluntario, la antigua estructura representativa, de la que sólo permanece, también como muestra de pragmatismo, la antigua Mutualidad Nacional de Funcionarios de la Administración Local. 


\section{APENDICE: ASOCIACIONES DE FUNCIONARIOS DE LA ADMINISTRACION LOCAL $\left({ }^{*}\right)$}

A) Asociaciones de ámbito estatal

a) Asociaciones generales

- Unión Federal Independiente de Trabajadores de la Administración Local (UFITAL) (BOE 28 de octubre de 1977).

- Unión de Sindicatos Independientes de Administración Local (BOE 13 de febrero de 1979).

b) Asociaciones sectoriales

- Asociación Profesional de Secretarios Habilitados al Servicio de Corporaciones Locales (BOE 6 de enero de 1978).

B) Asociaciones de Ámbito REgional

a) Asociaciones generales

- Federación de Sindicatos Asturianos de la Administración Local (BOE 21 de enero de 1978).

- Unión de Funcionarios de la Administración Local de Baleares (BOE 6 de junio de 1978).

- Sindicato Unitario de Funcionarios de la Administración Local (Región andaluza, Ceuta y Melilla) (BOE 26 de mayo de 1979).

b) Asociaciones sectoriales

- Asociación de Arquitectos e Ingenieros de Grado Superior al Servicio de las Corporaciones Locales de Alicante, Castellón de la Plana y Valencia (BOE 4 de enero de 1978).

- Asociación de Funcionarios del Cuerpo Técnico de Delineantes de la Administración Local (Provincias gallegas, Provincias castellanas de León, Zamora, Salamanca, Valladolid y de 1979. 
Palencia, Provincia de Logroño y Provincia de Oviedo) ( $B O E$ 6 de enero de 1978).

- Asociación Sindical de Aparejadores, Arquitectos Técnicos, Ingenieros Técnicos y Peritos al Servicio de las Corporaciones Locales de Alicante, Castellón y Valencia (BOE 28 de abril de 1978).

- Asociación Gallega de Técnicos en Arquitectura e Ingeniería de la Administración Local (BOE 14 de junio de 1978).

- Asociación de Funcionarios Técnicos de los Ayuntamientos de Asturias (FUTECA) (BOE 2 de octubre de 1979).

C) Asociaciones de Ámbito pRovinctal

a) Asociaciones generales

- Asociación Sindical Provincial de Funcionarios de la Administración Local (Badajoz) (BOE 24 de enero de 1979).

- Sindicato de Trabajadores de la Administración Local de la Provincia de Albacete ( $B O E 16$ de marzo de 1978).

- Asociación Profesional de Funcionarios de la Administración Local de la Provincia de Cáceres No Integrados en los Actuales Cuerpos Nacionales (BOE 10 de abril de 1978).

- Federación de Sindicatos de la Administración Local de la Provincia de Alicante (FASALPA) (BOE 16 de marzo de 1978).

- Sindicato Independiente de Funcionarios de la Provincia de Toledo (BOE 8 de mayo de 1978).

- Sindicato de Trabajadores de la Administración Local de la Provincia de Gerona (SINPAL) (BOE 3 de junio de 1978).

- Sindicato de Trabajadores y Funcionarios de la Administración Local de la Provincia de Córdoba (BOE 9 de junio de 1978).

- Sindicato de Trabajadores de la Administración Local de Guipúzcoa (STALGUI) (BOE 15 de junio de 1978).

- Sindicato Provincial de Funcionarios Trabajadores de la Administración Local de Burgos (BOE 16 de junio de 1978).

- Asociación Sindical Independiente de Funcionarios de la Administración Local de la Provincia de Ciudad Real (ASIFAL) (BOE 16 de junio de 1978).

- Asociación Profesional Independiente de Funcionarios de Administración Local de Castellón (BOE 26 de junio de 1978). 
LAS ASOCIACIONES SINDICALES DE FUNCIONARIOS EN LA ADMINISTRACION LOCAL 305

- Sindicato de Funcionarios de Administración Local de la Provincia de Pontevedra (BOE 1 de julio de 1978).

- Sindicato Independiente de Funcionarios de Administración Local de Valencia (BOE 6 de noviembre de 1978).

- Sindicato Independiente de Funcionarios, Empleados y Trabajadores de la Administración Local de la Provincia de Barcelona (BOE 23 de noviembre de 1978).

- Asociación Sindical de Funcionarios de la Administración Local de la Provincia de Salamanca (BOE 5 de mayo de 1979).

- Sindicato de Funcionarios de la Administración Local de la Provincia de Lugo (BOE 23 de mayo de 1979).

- Sindicato Independiente de Funcionarios de la Administración Local de la Provincia de Guadalajara ( $B O E 2$ de junio de 1979).

- Asociación Profesional de Funcionarios de la Administración Local de la Provincia de León (APROFAL) (BOE 2 de junio de 1979).

- Sindicato Provincial de Funcionarios de la Administración Local de Palencia (BOE 10 de octubre de 1979).

b) Asociaciones sectoriales

- Asociación Sindical de Arquitectos e Ingenieros Técnicos al Servicio de las Corporaciones Locales de la Provincia de Madrid (BOE 27 de mayo de 1978).

- Asociación Sindical de Aparejadores y Arquitectos Técnicos al Servicio de la Administración Local (ASFAL) (Madrid) (BOE 15 de julio de 1978).

D) Asociaciones vinculadas a Diputaciones provinciales

a) Asociaciones generales

- Asociación Sindical de Funcionarios de la Diputación Provincial de Santander (BOE 9 de diciembre de 1977).

- Sindicato de Funcionarios de la Excelentísima Diputación de Huelva (BOE 29 de marzo de 1978).

- Sindicato de Funcionarios de la Diputación Provincial de Oviedo (BOE 31 de marzo de 1978). 
- Sindicato Independiente de Trabajadores de la Diputación de Alicante (BOE 14 de abril de 1978).

- Asociación de Funcionarios de la Excelentísima Diputación de Huesca (BOE 8 de septiembre de 1978).

- Asociación de Funcionarios de la Diputación de Orense (BOE 12 de marzo de 1979).

- Asociación Sindical de la Excelentísima Diputación Provincial de Segovia (BOE 26 de abril de 1978).

- Sindicato de Funcionarios de Administración Local de la Excelentísima Mancomunidad Provincial Interinsular de Santa Cruz de Tenerife (BOE 28 de mayo de 1979).

b) Asociaciones sectoriales

- Asociación de Funcionarios del Departamento Técnico de la Diputación Provincial de Oviedo (FUTEC) (BOE 12 de septiembre de 1978).

- Asociación de Funcionarios Técnicos de Administración General de la Diputación Provincial de Madrid (BOE 12 de marzo de 1979).

- Asociación Sindical de Arquitectos e Ingenieros de la Excelentísima Diputación Provincial de Madrid (BOE 27 de febrero de 1979).

- Asociación de Funcionarios de Servicios Especiales del Parque Móvil de la Diputación de Madrid ( $B O E 12$ de marzo de 1979).

E) Asociaciones de Ambito comarcal

a) Asociaciones generales

- Asociación Sindical de Funcionarios de la Administración Local de Callosa de Segura (Alicante) y Comarca (BOE 28 de noviembre de 1977).

- Asociación Sindical de Funcionarios Trabajadores de la Administración Local de la Ciudad de Villena (Alicante) y Comarca (ASFAL) (BOE 9 de febrero de 1978).

- Sindicato de Trabajadores del Ayuntamiento de Alcoy y Comarca (Alicante) (BOE 3 de marzo de 1978). 
LAS ASOCIACIONES SINDICALES DE FUNCIONARIOS EN LA ADMINISTRACION LOCAL 307

- Sindicato de Trabajadores de la Administración Local de la Marina Baja (Alicante) (BOE 3 de marzo de 1978).

- Sindicato de Funcionarios de Administración Local de la Villa de Crevillente y Comarca (Alicante) (BOE 14 de abril de 1978).

- Sindicato de Trabajadores de la Administración Local de la Marina Baja (Alicante) (BOE 24 de abril de 1978).

- Sindicato de Trabajadores de la Administración Local de la SAFOR (Gandía y tres pueblos más) (Valencia) (BOE 11 de julio de 1978).

- Sindicato de Funcionarios de los Ayuntamientos de Belmonte, Candano, Grado, Las Requeras, Salas y Somiedo (Oviedo) (CUNAPI) (BOE 14 de agosto de 1978).

b) Asociaciones sectoriales

- Asociación de Funcionarios Locales al Servicio de Extinción de Incendios (Mallorca) (BOE 17 de enero de 1978).

F) Asociaciones DE Ámbito local

a) Asociaciones generales

- Asociación Profesional Sindical de Funcionarios de Administración Local de Las Palmas de Gran Canaria (BOE 6 de septiembre de 1977).

- Sindicato de Funcionarios de Administración Local de Avilés (SFALA) (BOE 17 de septiembre de 1977).

- Asociación de Funcionarios de Administración Local y Personal Contratado de Granollers (Barcelona) (BOE 1 de octubre de 1977).

- Sindicato de Trabajadores de Administración Local de Castrillón (Oviedo) (BOE 6 de octubre de 1977).

- Sindicato de Trabajadores de Administración Local de Siero (Oviedo) (BOE 25 de octubre de 1977).

- Sindicato de Trabajadores de Administración Local (SINTAL) de Gijón (BOE 7 de noviembre de 1977).

- Sindicato de Funcionarios del Ayuntamiento de Mieres (Ovie. do) (BOE 17 de noviembre de 1977). 
- Sindicato de Trabajadores de la Administración Local de San Martín del Rey Aurelio (Oviedo) (STALSMRA) (BOE 8 de noviembre de 1977).

- Sindicato de Funcionarios de la Administración Local de Laviana (Oviedo) (STALLA) (BOE 14 de noviembre de 1977).

- Sindicato de Funcionarios de la Administración Local del Ayuntamiento de Lena (Oviedo) ( $B O E 17$ de noviembre de 1977).

- Sindicato de Funcionarios de la Administración Local de Luarca (SFAAL) (Oviedo) (BOE 21 de noviembre de 1977).

- Sindicato de Trabajadores de la Administración Local de Gozón (Luanco) (Oviedo) (BOE 21 de noviembre de 1977).

- Sindicato de Trabajadores del Ayuntamiento de Oviedo (BOE 22 de noviembre de 1977).

- Sindicato de Funcionarios de la Administración Local del Ayuntamiento de Alicante (BOE 26 de noviembre de 1977).

- Sindicato de Funcionarios de la Administración Local de Langreo (SFALL) (Oviedo) (BOE 26 de noviembre de 1977).

- Sindicato de Trabajadores de la Administración Local de Cangas de Narcea (Oviedo) (BOE 2 de diciembre de 1977).

- Sindicato de Funcionarios Locales de Carreño (SINFALCA) (Oviedo) (BOE 7 de diciembre de 1977).

- Asociación de Funcionarios de la Administración Local de Mollet (Barcelona) (BOE 24 de enero de 1978).

- Asociación Sindical de Funcionarios de la Administración Local de Aller (Oviedo) (BOE 30 de enero de 1978).

- Sindicato de Trabajadores de la Administración Local de Benidorm (Alicante) (BOE 27 de febrero de 1978).

- Sindicato de Trabajadores de la Administración Local del Ayuntamiento de Monóvar (STALM) (Alicante) (BOE 11 de abril de 1978).

- Sindicato Local de Funcionarios y Trabajadores de la Administración Local del Ayuntamiento de Petrel (Alicante) (BOE 9 de mayo de 1978).

- Sindicato de Trabajadores del Ayuntamiento de Elche (STAE) (Alicante) (BOE 15 de mayo de 1978).

- Asociación de Funcionarios de Administración Local y Personal Contratado Administrativamente de Ripollet ( $B O E 1$ de junio de 1978). 
LAS ASOCIACIONES SINDICALES DE FUNCIONARIOS EN LA ADMINISTRACION LOCAL 309

- Sindicato de Trabajadores de la Administración Local de Ribadesella (Oviedo) (BOE 10 de junio de 1978).

- Sindicato Independiente de Funcionarios de Carrera y Empleo del Ayuntamiento de Alcira (Valencia) (BOE 1 de julio de 1978).

- Sindicato de Funcionarios de la Administración Local del Ayuntamiento de Burriana (Castellón) (BOE 13 de julio de 1978).

- Sindicato de Funcionarios de la Administración Local de Pravia (SFALPRA) (Oviedo) (BOE 9 de diciembre de 1978).

- Asociación de Funcionarios Públicos y Personal Contratado del Excelentísimo Ayuntamiento de Reus (BOE 28 de diciembre de 1978).

- Asociación Sindical de Trabajadores del Ayuntamiento de Bilbao (BOE 10 de enero de 1979).

- Asociación de Funcionarios del Excelentísimo Ayuntamiento de Melilla (BOE 12 de enero de 1978).

- Unión de Asociaciones de Funcionarios del Ayuntamiento de Madrid (BOE 25 de enero de 1979).

- Asociación de Funcionarios de Administración Local de Montornés del Vallés (Barcelona) (BOE 27 de febrero de 1979).

- Asociación de Funcionarios del Ayuntamiento de Ceuta No Pertenecientes a Cuerpos Nacionales (BOE 3 de abril de 1979).

- Asociación de Empleados del Ayuntamiento de Cambrils (Tarragona) (BOE 14 de mayo de 1979).

- Asociación Profesional de Funcionarios de Administración Local del Ayuntamiento de Santa Cruz de Tenerife (BOE 15 de mayo de 1979).

- Sindicato Independiente de Funcionarios del Ayuntamiento de Madrid (BOE 11 de junio de 1979).

- Sindicato de Funcionarios del Ilustre Ayuntamiento del Rosario (Santa Cruz de Tenerife) (BOE 30 de julio de 1979).

- Sindicato de Funcionarios del Ayuntamiento de San Miguel (Tenerife) (BOE 15 de octubre de 1979).

\section{b) Asociaciones sectoriales}

- Asociación Profesional Sindical de Funcionarios de Servicio de Asistencia Interna y Ceremonial del Ayuntamiento de Madrid (BOE 26 de noviembre de 1977). 
- Asociación Sindical de Funcionarios de los Servicios Técnicos Municipales de Madrid (FUSAL) (BOE 21 de enero de 1978).

- Asociación Profesional Sindical de Funcionarios Licenciados en Derecho al Servicio del Excelentísimo Ayuntamiento de Zaragoza (BOE 17 de junio de 1978).

- Asociación Sindical Profesional de Funcionarios del Subgrupo Administrativo del Ayuntamiento de Madrid ( $B O E$ 22 de diciembre de 1977).

- Asociación de Técnicos de Administración General y Técnicos Administrativos del Ayuntamiento de Madrid (BOE 24 de diciembre de 1977).

- Asociación Profesional Sindical de Funcionarios del Servicio de Talleres Generales y Parque Móvil del Excelentísimo Ayuntamiento de Madrid (BOE 20 de mayo de 1978).

- Asociación Sindical del Subgrupo de Auxiliares del Ayuntamiento de Madrid (BOE 6 de junio de 1978).

- Asociación Sindical de Técnicos de Grado Superior y Medio del Ayuntamiento de Zaragoza (BOE 20 de junio de 1978).

- Asociación Profesional Sindical de Funcionarios del Servicio de Colegios Nacionales e Instituciones Escolares del Ayuntamiento de Madrid (BOE 26 de junio de 1978).

- Asociación de Funcionarios de Administración General y Técnicos de Administración Especial del Ayuntamiento de Almería (BOE 30 de enero de 1979).

- Asociación Profesional Sindical de Funcionarios del Subgrupo de Administrativos y Auxiliares de Administración General y Otros Funcionarios de los Mismos Niveles 4 y 6 al Servicio del Excelentísimo Ayuntamiento de Zaragoza (BOE 20 de marzo de 1979). 
REVL-1980, núm. 206. SANCHEZ BLANCO, ANGEL. LAS ASOCIACIONES SINDICALES DE FUNCI...

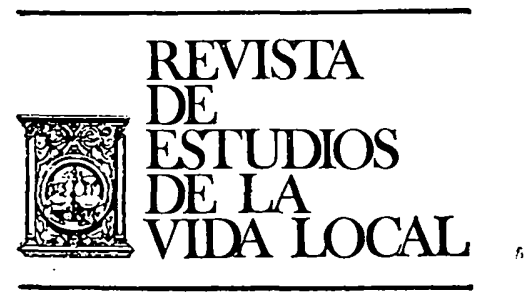

\section{CRONICAS}


REVL-1980, núm. 206. SANCHEZ BLANCO, ANGEL. LAS ASOCIACIONES SINDICALES DE FUNCI...

REVL-1980, núm. 206. SANCHEZ BLANCO, ANGEL. LAS ASOCIACIONES SINDICALES DE FUNCI... 